(232)

\title{
Evaluate the Efficiency of Bioballs and Ceramic rings for the Treatment of Industrial Wastewater
}

\author{
Kaushalya W.S.1* ${ }^{*}$ Bandara N.J.G.J. ${ }^{1}$, Rupasinghe S.K.L.S. ${ }^{2}$ \\ ${ }^{1}$ Department of Forestry \& Environmental Science, University of Sri Jayewardenepura, \\ Sri Lanka \\ ${ }^{2}$ Research \& Development Department, National Water Supply \& Drainage Board, \\ Rathmalana, Sri Lanka \\ *shehanikaushalya2@gmail.com
}

\begin{abstract}
Water pollution has become a severe global problem due to its direct and indirect consequences. The aquatic environment is continuously contaminated by a massive volume of hazardous and toxic substances generated by anthropogenic activities. Among several techniques, bioremediation is an eco-friendly, simple and cost effective technique to reclaim polluted water. The present study was conducted to investigate the water reclamation efficiency of commercially available bioballs and ceramic rings in terms of removing nutrients such as nitrogen and phosphorus and organic substances. The study was conducted in two parallel aerated reactors with the two different models of carrier media. The analysis was carried out to measure some physical $\left(\mathrm{pH}\right.$, Temperature) and chemical $\left(\mathrm{BOD}_{5}, \mathrm{COD}\right.$, TN, TP) parameters. Under Total Nitrogen, Nitrate-N and Nitrite-N, Ammonia-N and Kjeldhal-N were measured. Results of the study have revealed that the removal efficiencies of $\mathrm{BOD}_{5}, \mathrm{COD}, \mathrm{TN}$ and $\mathrm{TP}$ for ceramic rings were $87.94 \%, 80.10 \%, 75.21 \%$ and $73.84 \%$ respectively, for bioballs it was $86.76 \%, 72.31 \%, 71.92 \%$ and $68.06 \%$ respectively. The study showed that the both carriers were able to remove Ammonia-N content almost completely and simultaneously, the removal of organic matter (expressed as $\mathrm{BOD}_{5}$ and COD) was also sufficiently achieved.
\end{abstract}

Keywords: Bioballs, Ceramic rings, Bioremediation 